\title{
Qualche nota sui sermoni e sugli ammaestramenti antico-russi contro il paganesimo e i loro possibili rapporti con la letteratura apocrifa e gli scritti antibogomili
}

\author{
Simonetta Simi
}

This article is based on the examination of ancient Russian documents, "slova $i$ poučenija, napravlennye protiv jazyčestva«, and their relationships with the apocryphal, Bogomil and antibogomil literature.

Lo studio della tradizione mitologica dei popoli slavi presenta numerosi problemi: in primo luogo la mancanza quasi assoluta di fonti primarie. Come è stato notato più volte, le fonti del paganesimo slavo sono posteriori rispetto alla sua effettiva esistenza e sono in massima parte opera di osservatori esterni. Questa scarsità di materiale apre nuovi orizzonti di studio, propone molteplici possibilità interpretative, ma ha spesso dato luogo, soprattutto negli ultimi anni, a lavori pseudoscientifici (cfr. la riedizione della famigerata Velesova Kniga, un'opera senza dubbio inventata), assolutamente fantastici e privi di qualsiasi reale connessione con quella materia che tradizionalmente viene chiamata »mitologia slava.$^{1}$

Per evitare che la scarsità di documenti sul paganesimo slavo porti a ricercare spiegazioni e conferme in ambiti misticheggianti o leggendari occorre uno scrupoloso riesame delle fonti in nostro possesso: tra queste fondamentale importanza rivestono i cosiddetti slova i poučenija napravlennye protiv jazyčestva, sermoni e ammaestramenti scritti contro il paganesimo che rivelano quanto fossero vive nella memoria collettiva degli slavi orientali, ancora nei secoli XII-XIV, le antiche credenze pagane. Agli slova $i$ poučenija ${ }^{2}$ è dedicato questo contributo.

Le principali fonti inerenti alla tradizione slava orientale ${ }^{3}$ in nostro possesso sono costituite dalla Povest' Vremennych Let (XI sec.), dallo Slovo o polku Igoreve (XII sec.), da una copia paleo-russa della Chronika Ioanny Malaly (X sec.) ${ }^{4}$ e da SP tramandatoci in copie tarde (dal XIV al XVII secolo), ma risalente probabilmente ai secoli XI-XII. Tra queste è proprio SP a fornirci il maggior numero di informazioni sulla vita e le credenze dell'epoca. Gli Slova i poučenija, napravlennye protiv jazyčeskich verovanij $i$ obrjadov furono riuniti da Tichonravov nel quarto volume delle Letopisi russkoj literatury $i$ drevnostej (Mosca, 1862) e quindi ristampati da Ponomarev nel terzo fascicolo dei Pamjatniki drevnerusskoj cerkovno-učitel'noj literatury (1897). La raccolta di Tichonravov-Ponomarev fu, poi, ripresa dall'Azbukin nel »Russkij filologičeskij vestnik « di Varsavia in una trattazione, poco critica e non sostanziale,

1 N. Mikhailov, 1995, p. 5; N. Mikhailov, 2002, pp. 17-23.

2 D'ora in poi SP.

3 V.N. Toporov, 1998, p. 239.

${ }^{4}$ Svod drevnejšich pis'mennych izvestij o slavjanach, 1, (I-VI vv.), Moskva, 1991, p. 265. 
della lotta della Chiesa contro il paganesimo. Con la pubblicazione dei due volumi di Bor'ba christianstva s ostatkami jazyčestva $v$ Drevnej Rusi ${ }^{5} \mathrm{~N}$. Gal'kovskij analizzò gli scritti della raccolta di Tichonravov-Ponomarev, fornendo preziose informazioni sui manoscritti e sugli sborniki che li contengono. Ancora ad SP Aničkov dedicò nel 1914 la prima e la seconda parte dell'opera Jazyčestvo i drevnjaja Rus', dimostrando che nei documenti da lui pubblicati i dati relativi agli dèi russi non appartenevano alla redazione primitiva, ma furono interpolati più tardi. Nel 1922 alcune fonti riguardanti la religione pagana degli Slavi orientali, tra cui annali russi e cronache polacche, vennero parzialmente pubblicate (in lingua originale e traduzione tedesca) e commentate nel libro del finlandese V.J. Mansikka, Die Religion der Ostslaven, I. Quellen. Lautore cita ovviamente anche SP, ma si limita ad utilizzare l'elenco dei sermoni fornito da Gal'kovskij, senza alcuna informazione bibliografica. Per molti anni Mansikka risultò essere l'autore maggiormente citato e probabilmente il più conosciuto dagli studiosi. Forse per la scarsa reperibilità (almeno fino alla ristampa del 2000) del secondo volume di Gal'kovskij, Drevnerusskie slova i poučenija, napravlennye protiv ostatkov jazyčestva $v$ narode, SP fu conosciuto essenzialmente attraverso la sua pubblicazione.

Gli autori degli slova i poučenija si prefiggono il compito di ammaestrare i pagani attraverso citazioni del Nuovo e del Vecchio Testamento e attraverso le opere dei Padri della Chiesa. La propaganda della nuova fede si accompagna alla denuncia dei riti e delle credenze pagane. Indubbiamente, da questa acerba polemica religiosa non possiamo ricavare un quadro preciso e obiettivo delle usanze e dei riti dei popoli slavi prima della conversione; tuttavia, slova i poučenija contro il paganesimo ci forniscono, al di là degli intenti dei loro autori, preziose informazioni. In un periodo in cui i residui del paganesimo erano vivi nella memoria collettiva gli autori di SP sono costretti, per compiere la loro opera di evangelizzazione e rendere accettabile un insieme di norme altrimenti incomprensibile al mondo slavo di troppo recente conversione, a rammentare, condannandole, le antiche pratiche religiose e ad associarle a certune cristiane. Gli intenti polemici di questi evangelizzatori mantengono cosí in vita un duplice sistema culturale e spirituale, i loro sermoni e ammaestramenti codificano e documentano l'esistenza nell'ambito culturale slavo di un periodo in cui due diverse concezioni del mondo, due diverse religioni, pur contrastandosi, riuscirono a convivere ed addirittura a rafforzarsi vicendevolmente.

Com'è noto, l'adozione del cristianesimo non determinò affatto la sparizione del paganesimo, anzi: lo scontro tra paganesimo e cristianesimo fu molto aspro e originò come reazione l'opposizione "proprio-altrui«, quella, cioè, tra il paganesimo slavo e il cristianesimo greco-bizantino. Lopposizione non impedì tuttavia forme di sincretismo; il folclore, come sistema aperto e non normalizzato, assimilò molto dal cristianesimo: molte immagini e concezioni pagane, vive nella quotidianità del popolo, furono accostate a festività e a santi cristiani. ${ }^{6}$ Analogamente i residui del paganesimo,

5 Di particolare interesse è il fatto che la pubblicazione del secondo volume, Bor'ba christianstva s ostatkami jazyčestva v Drevnej Rusi. Drevnerusskie slova i poučenija, napravlennye protiv ostatkov jazyčestva $v$ narode (Mosca 1913), precedette di tre anni quella del primo, Bor'ba christianstva s ostatkami jazyčestva $v$ Drevnej Rusi (Char'kov 1916).

${ }^{6}$ Come è stato notato più volte da vari autori, il Profeta Elia assunse la funzione e l'aspetto di Perun, Paraskeva-Pjatnica quelli di Mokoš, mentre San Nicola quelli di Veles o di altri spiriti e divinità pagane; la festa del Semik, la Trinità, così come la Domenica delle Palme (Verbnoe Voskresen'e), e la festa di Ivan Kupala, che nella tradizione cristiana corrisponde alla nascita di San Giovanni Battista, mantennero il culto della 
o la continuazione delle tradizioni pagane, mantennero funzioni rituali chiave anche all'interno del cristianesimo. ${ }^{7}$

La cristianizzazione della Rus' pose fine all'esistenza ufficiale della mitologia slava, distruggendone il livello superiore, talché i personaggi che vi appartenevano iniziarono ad essere considerati come negativi e/o come facenti parte del sistema demonologico; ${ }^{8}$ il livello inferiore risultò invece più stabile e dette luogo a svariate combinazioni con la nuova religione cristiana dominante. In questa sfera bassa, non ufficiale, il paganesimo continuò ad esistere nella maggior parte delle terre slave, dove la fede negli dèi non vacillava, ma, anzi, veniva attualizzata dalla lotta della Chiesa contro di loro. Nel lungo periodo di transizione dal paganesimo al cristianesimo, definito già in $\mathrm{SP}$ dvoeverie ${ }^{9}(\mathrm{He}$ могу терпъть христіанъ, двоевърно живущихъ и върующихъ въ Перуна, въ Хорса и другихъ боговъ) ${ }^{10}$, dalla conversione ufficiale di Vladimir all'effettivo affermarsi della nuova religione fu soprattutto l'antica demonologia slava, l'insieme di dèmoni che non facevano parte del panteon »ufficiale« pagano a coesistere con il Dio e con i santi cristiani. ${ }^{11}$

Secondo la maggior parte degli studiosi, i documenti più antichi non nominavano mai le divinità pagane nella convinzione che il paganesimo fosse spento del tutto e che non fosse lecito rinnovarne la memoria. Nel corso dell'XI secolo si assistette però ad una rinascita pagana, non soltanto nella lontana periferia, ma nella stessa Kiev, ad opera dei volchvy (gli indovini); ${ }^{12}$ nacque di conseguenza la necessità di affrontare il paganesimo

vegetazione, quello del fuoco e dell'acqua. A questo proposito si vedano N.I. Tolstoj, 1998, p. 428; ma anche B. Uspenskij, 1982, pp. 31-112, 134-138, 150-156; V.N. Toporov, 1996, p. 167; Slavjanskie drevnosti, alla voce »dvoeverie«.

7 Il pane, elemento importantissimo nei festeggiamenti nuziali pagani (korovaj), sotto forma di eucarestia, rappresentò nella liturgia cristiana il Corpo di Cristo, l'acqua benedetta divenne fondamentale nel mistero del battesimo, quella santa fu considerata come il rimedio più efficace contro la presenza dei dèmoni, il fuoco e la fiamma furono concepiti come un sacrificio a Dio, la terra come l'essenza materiale del corpo umano. A questo proposito si vedano N.I. Tolstoj, 1998, p. 428; V.I. Toporov, V.V. Ivanov, 1974, pp. 243-258.

8 Secondo Ivanov e Toporov, all'interno della mitologia slava possono essere individuati diversi livelli a seconda delle funzioni dei vari personaggi mitologici, del loro carattere, dei loro rapporti con la collettività e del grado di individualizzazione delle loro realizzazioni. Il livello più alto è caratterizzato da un tipo più generalizzato di funzioni divine (giuridico-rituali, militari, economico-domestiche) e dai loro legami con il culto ufficiale (fino ai panteon delle prime compagini statali). Al livello più alto della mitologia slava appartengono ${ }^{*}$ Perunz e ${ }^{*}$ Veleš ai quali può essere collegato il personaggio femminile, Mokoš. Nel livello più alto possono essere inclusi l'antico-russo Svarogz (riferibile al fuoco è Svarožič, cioè, figlio di Svarogz), l'antico-russo Dažbogz e lo slavo meridionale Dabog (nel folclore serbo). Fanno parte del livello inferiore le divinità collegate al ciclo naturale (Rod ed altri, nella tradizione slava orientale) e la maggior parte di quelle femminili (rožanicy, bereginie, ecc.); le divinità del livello inferiore talvolta sono caratterizzate da un minore antropomorfismo rispetto a quelle del livello superiore, hanno funzioni più astratte e specializzate (Sud, il destino); si tratta di differenti classi di spiriti, animali e forze impure, poco individualizzati in stretto rapporto con tutto lo spazio mitologico, dalla casa, al bosco, alla palude; tra di essi annoveriamo: i domovye (spiriti della casa), i lešie (spiriti dei boschi), i vodjanye (spiriti delle acque), le rusalki (esseri femminili delle acque), le slavo-meridionali vile (spiriti dei vortici) etc. A questo proposito si vedano, V.V. Ivanov, V.N. Toporov, Slavjanskaja mifologija, in: Enciklopedičeskij Slovar', Slavjanskaja Mifologija, Moskva, 1995, pp. 1314. La numerazione di tali livelli ci sembra una cosa abbastanza convenzionale, a questo proposito, si veda anche la teoria sulla tripla funzionalità nel panteon pagano (Dumézil, 1987).

9 Questo fenomeno fu notato già nell'XI secolo dall'igumeno del Monastero delle Grotte a Kiev, Feodosij, il quale definí dvoeverie tale mescolanza di due diverse forme religiose. A questo proposito si veda, M.P. Novikov, 1991, pp. 80-81.

${ }^{10}$ Слово нгкоего Христолюбца. и ревнителя по правой вюрю, in N.M. Gal'kovskij, 1913, p. 41.

${ }^{11}$ N. Mikhailov, 1995, p.186.

${ }^{12}$ Aničkov, 1914, pp. 256-285; D. Angelov, 1979, pp. 418-420. 
in campo aperto, di descriverne le pratiche per meglio vituperarle, на раздровшениє льсти неприњзнинъ. на о8коръ твопАшимь таковағ. на по8чение правовърнымъ. И на причастье бо8до8шаго въка. посло8шаюшимъ книгъ сихъ. стыхъ. творашихъ дъломъ повєлънина въ шставлєниє гръховъ ${ }^{13}$. Ciò spiegherebbe l'interpolazione di passi relativi agli dèi pagani in documenti che inizialmente non scendevano affatto in particolari, ma si limitavano a condannare il paganesimo in modo generico.

Riportiamo a questo punto l'elenco preciso dei sermoni e degli ammaestramenti contro il paganesimo pubblicato da Gal'kovskij nel secondo volume di Bor'ba christianstva s ostatkami jazyčestva $v$ Drevnej Rusi. Drevnerusskie slova i poučenija, napravlennye protiv ostatkov jazyčestva $v$ narode (Moskva 1913, ristampa 2000):

1. О постп к невпжамь в понедюлокъ 2 недюли.

2. Слово св. Григорія, изобрптено въ толияюхъ $а$ томб, како первое погани суще Азыи кланалиса ідоломб і требы им клали.

3. Слово нгкоего Христолюбияа и ревнителя по правой вюргь.

4. Слово и откровеніе стых апль.

5. Слово сттго ойа намего I $\omega$ Златооустаго _о томг како первое погани впровали въ идоль и требы имь клали. Имена имь нарекали..

6. Св. отияа Кирилла слово о зльхъ дуспхъ.

7. Слово істолковано мвдростью $\omega$ стыхъ апль и прркъ. И дніи рекомомъ недюля.

8. Слово Исаил пророка истолковано стымб Ішанном Златоустомб о поставляющихъ вторую трапезу роду и рожаницамъ.

9. Статья румянцевскаго сборника, посвященная суевпріямб.

10. Статья »

11. Правила ш впрующихь в гады и звпри часовы имащцих дни овы добры $\omega в$ вы зльl.

12. Слово св. отець како подобаеть христіаномъ жити.

13. Краткія статьи, направленныя противъ волшебства и суевпрій.

14. Слово Златоуста о льчашихса в болюзни волхвованиемб и наоузы.

15. Слово св. отияа Моисея.

16. Слово стыхъ шиь о пость устава иерковнаго.

17. Слово св. Діонисія о жельющихъ.

18. Слово Іанна Златоуста да не излишне по младенцемъ плачемъ.

19. Вв субботу седьмую по пасии поученіе Іоан. Златоуста еже не плакати о умершихъ.

20. Слово св. Василія.

21. Поученіе Іоанна Златоуста о играхъ и плясаніи.

22. Поученіе христіаномь Іоанна Златоуста.

23. Слово св. Отеиъ, какъ духовно праздновати.

24. Слово о недюли блаженнаго Евсевія.

25. Слово св. штияа Ію̀ккова о дни стыя недюли.

26. Слово о постю ш велицимь и $\omega$ петровп говюньи ї $\omega$ филиповю.

27. Слово Іоанна Златоуста о христіанствю.

28. Слово св. Нифонта о русаліяхъ.

${ }^{13}$ Слово нюкоего Христолюбия и ревнителя по правой вюрп, in N.M. Gal'kovskij, 1913, p. 41. 


\section{9. Притча и заповюди гна.}

30. Слово Іоанна Милостиваго о исходюь души.

31. Слово св. Василія о постп.

32. О идолех владимировыхъ.

33. Поученіе въ понедплокъ стга дха.

34. Исповпдь каждаго чина по десятословію.

35. Слово учительно наказуеть о впровавшихъ въ стрпчу и чехъ.

Per quanto l'esistenza di altri sermoni e ammaestramenti non sia affatto esclusa, il corpus ricostruito da Gal'kovskij costituisce la base indispensabile per l'analisi del paganesimo degli antichi Russi per almeno due motivi: da un lato i sermoni, pur tramandatici in copie tarde, risalgono probabilmente ai secoli XI-XII così da risultare tra i documenti più prossimi all'epoca del paganesimo; d'altra parte, i loro autori sono interni alla tradizione slava, e le informazioni che ci forniscono probabilmente attendibili. Notevole è anche l'importanza filologica e linguistica dei codici che contengono SP dei secoli XIV-XVII, dal momento che testimoniano la presenza in questi testi tipicamente slavo-orientali di numerosi elementi di provenienza meridionale. Le parti che più dettagliatamente descrivono le tradizioni pagane, e soprattutto quelle che nominano le divinità del panteon slavo, sembrerebbero interpolazioni di copisti o compilatori, verosimilmente tratte da un'unica fonte (in tutto SP queste parti descrittive sono quasi identiche tra loro): riuscire a capire di quale fonte si tratti aiuterebbe ad attestare in modo autorevole la reale esistenza di certi riti, o divinità pagane.

La presenza in SP delle parti in cui vengono descritti gli usi, i costumi e le credenze degli antichi Slavi costituisce un'interessante rarità all'interno della letteratura antico-russa: attraverso questi passi possiamo ricavare informazioni sulla quotidianità e sulla vita dell'epoca. Posto che le interpolazioni di SP tramandate dai codici sono i passi che forniscono il maggior numero di dati sui culti e la "vita vissuta « dell'epoca, è importante stabilire quanto in SP (XIV-XVII) ci sia di originale e quanto sia ripreso da temi elaborati altrove, quale sia, cioè, il rapporto tra imitazione e rielaborazione nella letteratura russa antica. Prendiamo, dunque, in considerazione tre punti fondamentali: il rapporto tra SP e la tradizione scritturale (l'Apostolo); il rapporto tra SP e l'omiletica bizantina; il rapporto, in fine, tra SP e l'omiletica bulgara.

SP contro il paganesimo è composto secondo uno schema piuttosto fisso, di origine molto antica, che può essere rintracciato già nell'Apostolo; ${ }^{14}$ secondo questo schema viene proposto ai fedeli, con intenti educativi, un elenco dei peccati, o dei comportamenti peccaminosi, derivanti, secondo la concezione cristiana, dalla debolezza della natura umana. Solitamente lo schema prevede un elenco di peccati quali la calunnia, la diffamazione, l'invidia, la collera, l'ira, l'orgoglio, l'utilizzo di parole oscene e la partecipazione alle danze durante i banchetti, le rapine, le violenze, la vanità, l'amore impuro e la prostituzione, l'ubriachezza, la vendetta, la magia e i sortilegi, la golosità, l'assassinio, le superstizioni, i furti, l'avarizia e la cattiveria.

Il contenuto del corpus di SP registrato da Gal'kovskij, per quanto concerne le parti relative alle verità di fede, i dogmi fondamentali del cristianesimo e la dottrina dei Padri, ${ }^{15}$ in massima parte non si discosta dalla tradizione letteraria antico-russa; molti

\footnotetext{
${ }^{14}$ E.V. Petuchov, 1916, pp.3-4.

${ }^{15}$ V.N. Toporov, 1998, p. 33.
} 
sermoni e ammaestramenti sono anonimi, altri contengono il nome dei loro autori, altri ancora sono compilazioni tratte da fonti greche. Loriginalità di queste opere consiste proprio nel loro carattere di accusa nei confronti del paganesimo ed è, tuttavia, spesso limitata dall'utilizzo da parte degli autori di modelli letterari bizantini; la presenza di elementi riguardanti la quotidianità in tali documenti costituisce una rara eccezione e dipende, essenzialmente, dal talento di un particolare scrittore e dalla sua minore o maggiore indipendenza rispetto ai canoni letterari dell'epoca. Nella Rus' la nuova fede penetrò proprio grazie allo sviluppo di generi, già ampiamente valorizzati a Bisanzio, come l'omiletica; possiamo, tuttavia, rintracciare varie peculiarità della teologia russa antica rispetto a quella bizantina. ${ }^{16}$ Pur basandosi entrambe sulla patristica greca, la cultura della Rus' rimase pressoché estranea alle idee e ai metodi dei filosofi greci.

La presente trattazione è volta a rintracciare i possibili rapporti tra il corpus di SP contro il paganesimo e una serie di documenti appartenenti ad altre tradizioni mitologiche, folcloriche e letterarie; in particolar modo concentreremo la nostra attenzione sui rapporti che intercorrono tra la tradizione letteraria antico-russa e quella antico-bulgara nel periodo preso in esame. La situazione che si venne a creare nel momento in cui il popolo bulgaro ancora pagano dovette accettare la nuova fede, dopo l'865, è del tutto simile a quella descritta per la Rus' del X secolo. La sopravvivenza delle tradizioni pagane in Bulgaria è attestata dalle notizie contenute in prevalenza in opere di scrittori ecclesiastici della fine del IX secolo (Čudo na Sv. Georgi i bălgarina, un passo della traduzione bulgara della Cronaca di Manasse, le Responsa del pontefice Niccolò I alle interrogazioni dei bulgari, le varie Besedi e la Vita di Giorgio Agiorita). ${ }^{17}$

Il nostro intento è quello di confrontare questi documenti con gli slova $i$ poučenija, napravlennye protiv jazyčestva nella convinzione che il raffronto permetta di rintracciare interessanti similitudini. I sermoni e gli ammaestramenti antico-russi contengono infatti alcune "stranezze", che troverebbero una spiegazione nell'ipotesi di antigrafi slavo-meridionali. Mi riferisco a numerosi termini di evidente origine slava meridionale, alla costante menzione di vile, dive, samodive, samovile, navi ecc., chiaramente appartenenti alla tradizione mitologica slava meridionale ( и вър8ють в пер8на и в хорса и въ мокошь и в Сима и въ Рьгла и въ вилы их же числомъ $\vec{\Gamma} . \overrightarrow{\boldsymbol{\theta}}$. сестрбниць. ${ }^{18}$ ), al fatto che in molti sermoni e ammaestramenti si parli chiaramente dei Bulgari ${ }^{19}$ : не х8жьши с8ть жидовъ и єрєтикъ и болгаръ ижє въ въръ и во кршньї тако творать; ${ }^{20}$ словънє жє на свадьбахъ въкладываючє срамотоу и чєсновитокъ въ въдра пьють Ф өюфильскихъ жє и б аравитьскыхъ писанїй наоучьшєсА болгарє ғазыкъ сквьрнъишє и проклАтьишє е più avanti leggiamo бтоль начаша мыти гоузицъ срацини и болгарє й тьркмєни и шлико йхъ еّ̂сть въ въръ той. ${ }^{21}$ Anche in

${ }^{16}$ M. Garzaniti, 1988, pp.74-76.

${ }_{17}$ D. Angelov, 1979, pp. 81-94.

${ }_{18}$ Слово нпкоего Христолюбиа и ревнителя по правой вюрю, in N. Gal'kovskij, 1913, p. 41.

${ }^{19}$ Gli autori dei vari sermoni e ammaestramenti riconoscono nei Bulgari del Volga, di fede musulmana, coloro che hanno introdotto nella tradizione pagana slava determinati rituali.

${ }^{20}$ Слово нюкоего Христолюбиа и ревнителя по правой вюрюь, in N. Gal'kovskij, 1913, p. 41; ibidem, nota 17 , p. 45.

${ }^{21}$ Слово св. Григорія, изобрптено въ толияьхъ, in N. Gal'kovskij, 1913, p. 23-24; a questo proposito si veda anche D.A. Kazačkova, Kăm văprosa za bogomilskata eres v Drevna Rusija prez XI v., in: »Istoričeski Pregled «, n. 4, Sofija, 1957, pp. 45-78. 
Статья » книгъ срачиньскихъ и оть проклАтыхъ болгаръ. ${ }^{22}$

La presenza di divinità pagane di origine slava meridionale, le frequenti polemiche riguardo al rapporto tra Creatore e creazione (хто же бо можеть їзобръсти всен твари творены» ни шбраза оуказати свђтоу... тьм же ї философи халдъйстиі поучишасА тшетнымъ ї послужиша твари паче творца и поклонАхуть твари МнАши ББГИ а Ба творца не въдуша... да некланАітесА твари но творцю всъхъ вл̈дцъ... зане кланахутьсА идоломъ и твари і требы имь творАт ${ }^{23}$ ed il parallelo tra le genti pagane, gli eretici ed i Bulgari dovrebbe indurre ad indagare più attentamente sugli evidenti rapporti esistenti tra queste opere antico-russe (SP), gli apocrifi e gli scritti contro il bogomilismo. Nel noto apocrifo Choždenie Bogorodicy po mukam (anche questo testo, del resto, può essere considerato come uno scritto antibogomilo, cfr. N.A. Meščerskij, 1976, p. 185) ${ }^{24}$ non può non farci riflettere il passo: та оутриґа троњ на хърса вєлєса пєроуна. на Бы venne aggiunto dall'ignoto traduttore bulgaro per stigmatizzare il paganesimo ancora perdurante in Bulgaria; ${ }^{26}$ è interessante notare a questo proposito la stretta coincidenza di un passo dello Слово и откровеніе стых апль (мнашє Богы. многы пєроуна и Хорса дыА, тролна, и инги мнови ${ }^{27}$ con quello già citato sulle divinità dello Слово нгкоего Христолюби, (Gal'kovskij, p. 41). Le credenze pagane, mantenutesi vive in seno alla popolazione bulgara, sono riflesse con particolare chiarezza in alcuni degli apocrifi sorti in terreno bulgaro durante i secoli XI-XII. Evidente è, inoltre, sempre in Слово нгккоего Христолюбиа la coincidenza con un passo del Videnie apostola

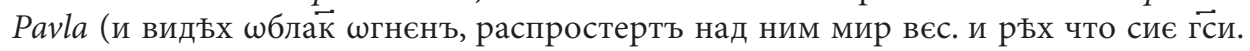
и рєчє сє $\overrightarrow{\epsilon с}$ бєзакониє смъшено съ мл̈твою грбшных). ${ }^{28}$ Leredità pagana che si era conservata a lungo tra la popolazione bulgara (e che fu particolarmente forte tra la fine del IX e l'inizio del X secolo) fu un terreno favorevole per la nascita di tendenze ereticali ed antiecclesiastiche; le credenze pagane in esseri demoniaci contribuivano a minare il monoteismo cristiano ed a rafforzare la concezione dualistica del mondo, secondo cui il mondo visibile era sottomesso all'autorità del diavolo. Senza aver avuto alcun ruolo costruttivo nella nascita del bogomilismo, l'ancor vitale paganesimo aveva creato condizioni favorevoli alla sua diffusione. Questa situazione si riflette esattamente nella Rus' dei secoli X-XI; a partire dall'XI secolo, infatti, la dottrina bogomila aveva cominciato ad esercitare la sua influenza anche nella Rus' kieviana. L'affinità etnica e linguistica, esistente tra Bulgari e Russi, era un valido presupposto per la creazione di condizioni favorevoli al contatto tra i due popoli e ad una reciproca influenza. Lo stato di Kiev, realizzandosi secondo il modello bizantino, era definitivamente entrato

22 N. Gal'kovskij, 1913, p. 97.

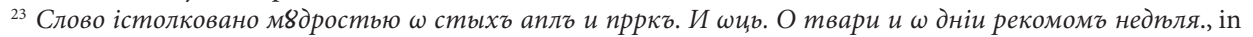
N. Gal'kovskij, 1913, pp. 76-83; cfr. Слово св. Григорія, изобрптено въ толипхъ, in N. Gal'kovskij, 1913, p. 17-35; anche secondo E. Aničkov (1914, pp. 297-298, 120-123) nella lotta contro il paganesimo ci si avvalse delle stesse accuse rivolte nei confronti delle eresie manichee e bogomile.

${ }^{24}$ V.V. Mil'kov, 1999, p. 121.

${ }^{25}$ V.V. Mil'kov, 1999, pp. 583-597.

${ }^{26}$ D. Angelov, 1979, p. 88.

${ }^{27}$ N. Gal'kovskij, 1913, p. 51.

${ }^{28}$ V.V. Mil'kov, 1999, pp. 535; per un confronto cfr. N. Gal'kovskij, 1913, p. 43 (и видъх шблак кровавъ, распростертъ надо всъмъ миромъ и воспросихъ глА гси что сє єсть и рєчє ми сє єсть мЛ̈тва члвчьска смЂшєна с бєзакониємь). 
in seno a quella cultura dell'est ortodosso, alla quale la Bulgaria medievale aveva da tempo aderito. Dalle terre bulgare partí un flusso incessante di opere letterarie; tra queste opere c'erano non solo monumenti letterari ufficiali, destinati ai bisogni della Chiesa e dell'aristocrazia, ma anche opere di carattere popolare, con contenuti apocrifi o eretici, sorte in Bulgaria sotto l'influsso della dottrina bogomila. Come testimoniano le cronache, negli anni 1024, 1066-1068, 1088 si svilupparono una serie di sommosse strettamente collegate all'insorgere di una reazione pagana (volchvy) contro la Chiesa e la religione cristiana ufficiale. L'insoddisfazione aveva cominciato a manifestarsi sotto forma di concezioni e predicazioni dualistiche. Il breve brano sotto l'anno 1071 testimonia chiaramente la concezione dualistica dominante fra i volchvy; ${ }^{29}$ il passo noto come Povestvovanie o volchvach si costruisce sulla base di un materiale letterario già preparato, è evidente in essa l'influenza delle cosiddette »favole bulgare « e delle opere apocrife $^{30}$; nella gran parte di SP vi si fa riferimento, la Статья » в вдвновеніи духх $\tilde{\beta}$ члвкащ, per esempio, attesta: сицє бо нъціи ерєтици глаголют б книгъ срачиньскихъ и отъ проклатыхъ болгаръ. Troviamo lo stesso tipo di citazioni anche in Слово св. Григорія, изобрптено въ толияюхъ dove è scritto: того жє шсирида скажєть книга лъживан и сквьрньнағ... бтоль начаша мыти гоузицъ сарацини и болгарє; lo stesso significato hanno citazioni del tipo кош8ны еллинскіА и басни жидовскіА dello Слово стпго ойа нашего І $\omega$ Златооустаго - о томъ како первое погани вгоровали въ идоль и требь имъ клали. Имена имъ нарекали, оppure del tipo поганїи єлини dello Св. отиза Кирилла слово о зльхъ дуспхъ е del Поученіе христіаномъ Іоанна Златоуста, del Притча и заповпди гна. ${ }^{31}$ Sia in SP contro il paganesimo che in Beseda presvitera Kozmy, gli aggettivi elleni, giudei, saraceni o bulgari, significano eretici, non conformi alla dottrina ortodossa; nella Статья » вд8новеніи духха $\tilde{B}$ члвка« si esprime chiaramente quale sia la colpa più grande degli eretici: Всьм бо єсть Творєцъ Богъ, а нє родъ.. Єдин вдымаєть всєдръжитєль. ижє єдинъ бєзсамратєнъ и нє погибаюшихъ тврєцъ.. (еретики) не раз8мъша Творца своєго, създавшаго их и вдохн8вшаго въ нихъ д8хъ жизни. ${ }^{32}$ La lotta contro le eresie del tempo è il motivo

${ }^{29}$ Povest' vremennych let, I, Moskva, 1950, p.118.

${ }^{30}$ V.V. Mil'kov, 1999, p. 96. Ci permettiamo di dissentire con l'interpretazione di Mil'kov riguardo alle poco rilevanti coincidenze tra i »libri bulgari«, il Povestvovanie o volchvach e, quindi, anche tutti gli slova i poučenija napravlennye protiv jazyčestva ad essa correlati. Sebbene, infatti, come afferma il Mil'kov (Mil'kov, 1999, p. 101) l'annalista non identifichi le eresie bulgare con il paganesimo, crediamo con questo breve articolo di aver già addotto sufficienti prove su quanto le eresie bulgare, e più propriamente gli scritti antibogomili (stranamente si veda lo stesso Mil'kov, 1999 a p. 105), siano strettamente connessi alle testimonianze tramandateci sulle credenze e gli usi del paganesimo slavo (ricordiamo l'equivalenza semantica evidente nei sermoni tra gli aggettivi bulgari, pagani, elleni ed eretici). A questo proposito si confrontino, inoltre, i numerosi passi della Beseda Kozmy alle pp. 99-100, 102, 103, 111, 117, 122, 123-125, 133, 143, 145, 153-154, 158, 163-164 dell'edizione di A. Vaillant, Le traité de Cosmas, in Textes vieux-slaves, Paris, 1968.

${ }^{31}$ N. Gal'kovskij, 1913, p. 97, 24, 61, 68, 188, 275.

${ }^{32}$ Riguardo al rapporto del passo citato con quello del Povestvovanie o volchvach, si veda V.V. Mil'kov, 1999, pp. 358-365 ed in particolar modo pp. 95-96. Ci permettiamo ancora una volta di notare che troppo spesso il Mil'kov assimila gli slova i poučenija napravlennye protiv jazyčestva, perdendo di vista il loro ruolo e le loro funzioni, con una più generica concezione slavo-pagana del mondo; proprio concordando con la premessa dell'autore, sul fatto, cioè, che il Povestvovanie o volchvach non possa essere considerato come una testimonianza dei movimenti eretici medievali, riaffermiamo la sua stretta correlazione con i sermoni e gli ammaestramenti contro il paganesimo. Il Povestvovanie costituisce un utile riferimento cronologico per testimoniare la »rinascita « del paganesimo nella Rus', lo stesso autore del resto, più avanti (cfr. Mil'kov, 1999, pp. 105-106), afferma che il carattere dualistico non appartiene ai volchvy, ma ai loro oppositori; ci pare ancora una volta, doveroso precisare che proprio nell'intento polemico degli autori di SP contro il paganesimo 
principale utilizzato come modello in SP, ma si riflette anche nella letteratura canonica (Kormčaja kniga, Chudye nomokanuncy) e nella formazione dei vari indici in cui venivano incluse le opere che la Chiesa aveva dichiarato nocive ed inadatte alla lettura. ${ }^{33}$ Gli autori di SP si mostrano come »difensori della retta fede«, portatori della teologia cristiana trinitaria, essi lottano contro l'estendersi di ogni manifestazione divina al di fuori delle tre Persone, cosa che condurrebbe al politeismo delle genti pagane; per essi l'accettazione della fede trinitaria costituisce la conditio sine qua non per essere ammessi al battesimo e, quindi, alla comunione con Cristo. Di grande aiuto al clero russo nella lotta contro gli eretici furono la Beseda presvitera Kozmy (X-XIII secc.) e tutta una serie di opere antiereticali composte in Bulgaria quali: Pis'mo patriarcha konstantinopol'skogo Feofilacta carju Bolgarii Petru, Sinodico della domenica dell'ortodossia, Sull'attività dei demoni di Psello, Contro i Bogomili di Eutimio Zigabeno, Sinodico dello zar Boril, Codice di Stefano Dušan, ecc. ${ }^{34}$ Prendendo, per il momento, come esempio la Beseda presvitera Kozmy, possiamo immediatamente rintracciarvi numerose e consistenti somiglianze sia con lо Слово нпкоего Христолюбиа и ревнителя по правой вюри, che con lo Слово стгго ойа нашего І $\omega$ Златооустаго - о томъ како первое погани вгоровали въ идоль и требы имъ клали. Имена имъ нарекали. Innumerevoli sono le parti della Beseda che immediatamente ci rimandano al corpus di SP (vedi nota 30, p. 10), la coincidenza delle citazioni neotestamentarie nei vari documenti è impressionante e molto simili risultano essere le descrizioni degli usi e dei costumi delle genti pagane e degli eretici bogomili. La struttura dei tre componimenti è quasi identica, l'intento degli autori delle tre opere è comune e consiste sempre nel voler ammaestrare le genti nella retta fede, denunciando le atrocità commesse dagli eretici; come già detto, per eretici si intendono anche i pagani, è in quest'ottica, appunto, che paganesimo ed eresie si mescolano e che le influenze dell'uno sulle altre si fanno sempre più evidenti.

\section{Letteratura}

Afanas'ev A.N., Poetičeskie vozzrenija slavjan na prirodu, I-III, Moskva, 1865-1869.

Angelov D., Il Bogomilismo. Un'eresia medievale bulgara (titolo originale: Bogomilstvoto $v$ Bălgarija), Roma, 1979.

Aničkov E.V., Jazyčestvo i drevnjaja Rus', Sankt-Peterburg, 1914.

e nella sua funzione consiste il principale legame con le opere di carattere dualistico (scritti bogomili, o meglio ancora, antibogomili).

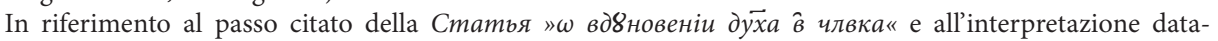
ne dal Mil'kov (Mil'kov, 1999, pp. 95-96, 101-102), concordiamo pienamente con lo studioso sul fatto che ideologicamente la concezione cosmogonica slavo-pagana non sia identica a quella bogomila, ma dobbiamo dissentire fortemente sull'assenza di un'opposizione dualistica all'interno del paganesimo slavo; come potremmo considerare la ricostruzione dell'osnovnoj mif (Ivanov, Toporov, 1974), presente in tutte le tradizioni, se non come manifestazione di un'opposizione dualistica? L'affermazione, inoltre, che Rod non possa essere assimilato né ad un Bog-Tvorec, né al suo antipodo Bes, ci lascia piuttosto perplessi; Rod fa indubbiamente parte del livello inferiore del paganesimo slavo, non può, dunque, essere considerato come una divinità superiore. La possibile confusione tra Rod, come divinità che genera la vita, e un Bog-Tvorec è chiaramente ascrivibile ad un'interpretazione cristiana posteriore.

${ }^{33}$ Riguardo agli indici, si veda D. Angelov, 1979, pp. 423-424, 74 e sgg.

${ }^{34}$ D. Angelov, 1979, pp. 11-36. 
Azbuкin M., Literaturnoj bor'by predstavitelej Christianstva s ostatkami jazyčestva v russkom narode (XI-XIV vek), 1896.

Begunov Ju.K., Kozma presviter v slavjanskich literaturach, Sofija, 1973.

BrüCKner A., Mitologia slava (titolo originale: Mitologia słowiańska), Bologna, 1923.

BusLAEv F., Istoričeskaja christomatija, 1861.

DumézIL G., Tridelna ideologija indoevropcev, Ljubljana, 1987.

GaL'Kovskij N.M., Bor'ba christianstva s ostatkami jazyčestva v drevnej Rusi, vol. I, Char'kov, 1916.

Gal'kovskij N.M, Drevnerusskie slova i poučenija, napravlennye protiv ostatkov jazyčestva v narode, Moskva, 1913.

Garzaniti M., Il cristianesimo in Russia da Vladimir a Pietro il Grande, Roma, 1988.

Impellizzeri S., La letteratura bizantina da Costantino a Fozio, Milano, 1993.

IvANOV J., Bogomilski knigi i legendi, Sofija, 1925.

Ivanov V.V., Toporov V.N., Issledovanija $v$ oblasti slavjanskich drevnostej, Moskva, 1974.

Ivanov V.V., Toporov V.N., Slavjanskaja mifologija, in: Slavjanskaja Mifologija, Enciklopedičeskij slovar', Moskva, 1995.

Ivanov V.V., Toporov V.N., Slavjanskie jazykovye modelirujuščie semiotičeskie sistemy, Moskva, 1974.

KaZaČKova D.A., Kăm văprosa za bogomilskata eres v Drevna Rusija prez XI v., in: »Istoričeski pregled «, n. 4, Sofija, 1957.

Levkievskaja E.E., Nizšaja mifologija slavjan, in: Očerki istorii kultury slavjan, Moskva, 1996.

LichačEv D.S., Povest'vremennych let po Lavrent'evskoj letopisi, Moskva-Leningrad, 1950.

Łowmiański H., Religia Słowian i jej upadek, Warszawa, 1979.

Mansikka V.J., Die Religion der Ostslaven, 1, Quellen, in: Folklore Fellow Communications, n.43, Helsinki, 1922.

Meriggi B., Il concetto del Dio nelle religioni dei popoli slavi, in: »Ricerche slavistiche«, 1, Roma, 1952.

Meriggi B., La preghiera slava pagana, Firenze, Olschki, 1961.

Meriggi B., Scritti minori, Brescia, 1975.

Migne J.P., Patrologiae Cursus Completus, Series Graeca, Parisiis, 1844-1866.

Mil'kov V.V., Drevnerusskie Apokrify, Sankt-Peterburg, 1999.

Mikhailov N., A proposito di una interpretazione del teonimo slavo ${ }^{*}$ Perun, in: Ricerche slavistiche«, voll.XXXIX-XL, Roma, 1992-1993.

Mikhailov N., Lett. nave, lit. novis, altruss. ${ }^{\star}$ navı̆ u. a. Zum Problem der Realisierung eines balto-slawischen (Ur)stammes auf der mythologischen Ebene, in: „Ponto-baltica«, n. 6, Accademia Toscana di Scienze e Lettere »La Colombaria«, 1995.

Mikhailov N. (a cura di), Mitologia slava, in: Studi slavi, n. 1, II ed., Pisa-Genova, ECIG, 1995.

Mikhailov N., Mythologia slovenica, Trst, 2002.

Moreschini C., Omelie sulla natività, Città Nuova Editrice, Roma, 1983.

Novikov M.P., Christianizacija kievskoj Rusi: metodologičeskij aspekt, Moskva, 1991.

Oinas Felix J., Essay on Russian Folklore and Mythology, Russian Poludnica »midday spirit«, Slavica Publishers, Inc., Columbus, Ohio, 1985. 
Petrović M.M., Kudugeri-Bogomili u vizantijskim i srpskim izvorima $i$ »Crkva bosanska«, Beograd, 1998.

Petruchin V.Ja, Drevnjaja Rus'. Narod. Knjaz’ja. Religija, in: Iz istorii russkoj kul'tury, vol. I (Drevnjaja Rus'), Moskva, 2000, pp.13-410.

Petuchov E.V., Russkaja literatura, istoričeskij obzor glavnejšich literaturnych javlenij drevnego i novago perioda, Petrograd, 1916.

SreZnevskij I.I, Drevnie pamjatniki russkogo pis'ma i jazyka, Spb, 1863.

SreZnevskij I.I, Svedenija i zametki o maloizvestnych $i$ neizvestnych pamjatnikach, Spb, 1871.

Sreznevskij I.I., Svidetel'stva Paisievskogo sbornika o jazyceskich sueverijach Russkich, n. 5, Moskvitjanin, 1851.

ŠACHмatov A.A., Polnoe sobranie russkich letopisej, lavrentevskaja letopis' i suzdal'skaja letopis' po akademičeskomu spisku, vol. I, II ed., Moskva, 1962.

Stara Bălgarska literatura, vol. I, Apocrifi, Sofija, 1981.

Svod drevnejšich pis'mennych izvestij o slavjanach (I-VI vv.), vol. I, Moskva, 1991.

Tichonravov N.K., Slova i poučenija, napravlennye protiv jazyčeskich verovanij i obrjadov, in: Letopisi russkoj literatury i drevnosti, vol. IV, Moskva, 1862.

Tichonravov N.K., Pamjatniki otrečennoj russkoj literatury, vol. II, Moskva-S.Peterburg, 1863.

Tolsto N.I., Jazyčestvo drevnich slavjan, in: Očerki istorii kultury slavjan, Moskva 1996.

Tolsto N N.I., Jazyčestvo i christianstvo drevnej Rusi, in: Izbrannye Trudy, slavjanskaja literaturnojazykovaja situacija, II, Moskva, 1998.

Tolsto N.I., Jazyk i narodnaja kul'tura, Moskva, 1995.

Tolsto N.I., Slavjanskie verovanija, in: Slavjanskaja Mifologija, Enciklopedičeskij slovar', Moskva, 1995.

Toporov V.N., Bogi drevnich slavjan, in: Očerki istorii kultury slavjan, Moskva, 1996.

Toporov V.N, Nekotorye voprosy izučenija slavjanskoj mifologii, in: »Studia Mythologica Slavica«, 1, Ljubljana, 1998.

Toporov V.N., Predistorija literatury u slavjan: opyt rekonstrukcii. Vvedenie $v$ kursistorii slavjanskoj literatury, Moskva, 1998.

Toporov V.N., Svjatost' i svjatye v russkoj duchovnoj kul'ture, vol. I-II, Moskva, 19951998.

Uspenskij B.A., Filologičeskie razyskanija v oblasti slavjanskich drevnostej, Moskva, 1982.

Vaillant A., Textes vieux-slaves, Paris, 1968.

Zelenin D., Očerki russkoj mifologii, Petrograd, 1916.

\section{Testi di riferimento}

Bălgarska Mitologija: enciklopedičen rečnik, Sofija, 1994.

DAL' V., Tolkovyj Slovar' Živogo Velikorusskogo Jazyka, voll. I-IV, Moskva, 1981.

Dizionario delle letterature classiche, Giulio Einaudi Editore, Torino, 1993, (titolo originale: The Oxford Companion to Classical Literature).

Mifologičeskij slovar', a cura di E.M. Meletinskij, Sovetskaja Enciklopedija, Moskva, 1990. Mify narodov mira, I-II, Moskva, 1991-1992. 
Polnyj Pravoslavnyj Bogoslovskij Enciklopedičeskij Slovar', voll. I-II, Moskva, 1992.

Slavjanskaja mifologija, Enciklopedičeskij slovar', Moskva, 1995.

Slavjanskie drevnosti, (pod. red. N. I. Tolstogo), I-II, Moskva 1995-1999.

Slovar' knižnikov i knižnosti drevnej Rusi, vol. I, Leningrad, 1987.

Slovar' Russkogo Jazyka, voll. XI-XVII, Moskva, 1975.

SREZneVskij I.I., Slovar' drevne-russkago jazyka, Graz, 1956.

VAsmer M., Russisches etymologisches Wörterbuch, Bd. I-III, Heidelberg, 1950, (trad. russa, Etimologičeskij slovar' russkogo jazyka. Perevod s nemeckogo i dopolnenija člena-korrespondenta AN SSSR O.N. Trubačeva, voll. I-IV, Moskva, 1986-1987).

\section{Некоторые заметки о древнерусских „Словах и Поучениях направленных против язычества« и их возможные взаимоотношения между апокрифической литературой и антибогомильскими писаниями.}

\section{Симонетта Сими}

В центре внимания предлагаемой статьи - анализ ряда Слов и Поучений, направленных против язычества (далее С. и П.). Нас в этом исследовании будет интересовать перечень древнерусских произведений из корпуса С. и П., перепечатанныхН.М.Гальковским во втором томе его книги» БорьбаХристианства с остатками язычества в Древней Руси« (Москва 1913), их история, описание их роли и функции в древнерусском литературном ареале. С. и П., с которыми мы ознакомились, дают, обличая языческие обычаи, наглядное представление об особенностях идейно-религиозной обстановки на Древней Руси в первые века послевведения Христианства.Нашацель- обнаружить взаимоотношения междуС. и П. и апокрифами, богомильскими и антибогомильскими книгами, пришедшими из Болгарии. Апокрифическая, богомильская и антибогомильская литература проникла в древнерусскую книжность разными путями и довольно интенсиво, попав на русскую почву от южных славян, получила широкое распространение, оказав ощутимое влияние на формирование древнерусской христианской культуры. 